\title{
Enkephalin-, thyrotropin-releasing hormone- and substance P-immunoreactive axonal innervation of the ventrolateral dendritic bundle in the cat sacral spinal cord: an ultrastructural study
}

\author{
V. Ramírez-León*a ${ }^{\mathrm{a}}$, T. Hökfelt ${ }^{\mathrm{a}}$, A.C. Cuello ${ }^{\mathrm{b}}$, T.J. Visser ${ }^{\mathrm{c}}$, B. Ulfhake ${ }^{\mathrm{a}}$ \\ "Department of Neuroscience. Karolinska Institutet, S-171 77 Stockholm. Sweden \\ ${ }^{b}$ Department of Pharmacology and Therapeutics, McGill University. Montreal, Canada \\ ${ }^{C}$ Department of Internal Medicine and Clinical Endocrinology, Erasmus Lniversity Medical School, NL-30(0) DR Rotterdam. The Netherlands
}

Accepted 30 June 1994

\begin{abstract}
The distribution and synaptic arrangement of thyrotropin-releasing hormone-, substance $\mathbf{P}$ - and enkephalin-immunoreactive axonal boutons have been studied in the ventrolateral nucleus (Onuf's nucleus) of the upper sacral spinal cord segments in the cat. For this purpose, the peroxidase-antiperoxidase immunohistochemical technique was used. Immunoreactive axonal boutons were traced in complete series of sections in order to reveal synaptic contacts with the bundled dendrites of the ventrolateral nucleus. As judged from the cross-sectional diameter of the postsynaptic dendrites, the distribution of immunoreactive boutons was nonrandom. Enkephalin-immunoreactive axonal boutons, presumed to be mostly of segmental origin, displayed a rather restricted distribution to mainly ( $>80 \%$ ) medium-to-large dendrites. Thyrotropin-releasing hormone-immunoreactive boutons, that derive from supraspinal levels, were also found to impinge on medium-to-large dendrites $(>80 \%)$, indicating a proximal location within the dendritic trees. The skewness toward large postsynaptic dendrites was even more marked for thyrotropin-releasing hormone- than for enkephalin-immunoreactive boutons. Substance P-immunoreactive boutons, that are of either supraspinal or spinal origin, showed a more even distribution throughout the dendritic trees, including both thin distal branches and thick proximal dendrites. In view of the well-known fact that virtually all thyrotropin-releasing hormone-immunoreactive boutons in the ventral horn cocontain substance $P$ (and serotonin) it was assumed that substance P-immunoreactive boutons in synaptic contact with the finestcalibre dendrites as well as most of those with a very proximal juxtasomatic location on the dendritic trees were of segmental origin, while those impinging on medium-to-large dendrites could be of either spinal or supraspinal origin. Fine-calibre dendrites $(<1$ $\mu \mathrm{m}$ ) represent about $25 \%$ of the dendritic branches in the ventrolateral nucleus, but receive, with the exception of substance $\mathrm{P}(8 \%)$, very little $(<3 \%$ ) peptidergic or GABAergic (Ramírez-León and Ulfhake, 1993) input, although the degree of dendritic membrane covering by bouton profiles in the ventrolateral nucleus does not seem to vary much with the calibre of the postsynaptic dendrite (Ramirez-León and Ulfhake, 1993). Both substance P- and enkephalin-immunoreactive axonal boutons established synaptic contact with more than one dendrite. Furthermore, one and the same bouton could be found in contact with two dendrites that were coupled to each other by a dendro-dendritic contact of desmosomal or puncta adherentia type. This synaptic arrangement was, however, not seen among thyrotropin-releasing hormone-immunoreactive boutons, indicating that these axonal boutons act on a single postsynaptic element, while inputs intrinsic to the spinal cord can show a divergence also at the terminal level.
\end{abstract}

Keywords: Motoneuron; Synaptic input; Dendro-dendritic contacts; Peroxidase-antiperoxidase technique; Pelvic muscles: Electron microscopy

\section{Introduction}

In the cat, the striated muscles of the pelvic floor and the external sphincters are innervated by motoneurons

\footnotetext{
* Corresponding author. Tel: +46 8 7287888; Fax: +46 8333968 ; E-mail: brun.ulfhake@neuro.ki.se.
}

located in two clearly defined motor nuclei of the sacral spinal cord (e.g. Onuf, 1900; Romanes, 1951; Ueyama et al., 1984): the ventromedial nucleus (VMN; supplying the levator ani and the bulbospongiosus muscles; Sato et al., 1978) and the ventrolateral nucleus (VLN; supplying the sphincter urethrae, the sphincter ani externus and the ischiocavernosii muscles; Sato et al.. 1978; Kuzuhara 
et al., 1980). A characteristic of the VMN and VLN is that their motoneuron dendrites are arranged into rostro-caudally running dendritic bundles (e.g. Scheibel and Scheibel, 1970; Matthews et al., 1971; Dekker et al., 1973; Kerns and Peters, 1974; Anderson et al., 1976; Konishi et al., 1978; Schrøder, 1980; for review, see Roney et al., 1979). The functional significance of the dendritic bundle formations has not been established, but it has been suggested that the frequently occurring dendro-dendritic contacts (see e.g. Matthews et al., 1971; Kerns and Peters, 1974) may indicate sites for information transfer.

According to several studies, both the VMN and VLN are innervated by classical transmitters, such as 5-hydroxytryptamine (5-HT, serotonin) and noradrenaline (e.g. Kojima et al., 1984, 1985; Micevych et al., 1986; Tashiro et al., 1989a,b), as well as by neuropeptides, such as substance P (SP), enkephalin (ENK) and somatostatin (e.g. Glazer and Basbaum, 1980; Hunt et al., 1981; Erdman et al., 1984; Schrøder, 1984; Konishi et al., 1985; Micevych et al., 1986; Tashiro et al., 1989a,b). Thyrotropin-releasing hormone (TRH), a peptide that has been shown to coexist with 5-HT in axons in the ventral horn of the spinal cord (Appel et al., 1987; Staines et al., 1988; Arvidsson et al., 1990; Wessendorf et al., 1990), has only been reported in the VLN of primates (Lechan et al., 1984; Rajaofetra et al., 1992).

The VLN motoneurons have properties that make them different from other somatic motoneurons; they are for example selectively spared even in advanced stages of amyotrophic lateral sclerosis (ALS; see e.g. Mannen et al., 1977; Sung, 1982). Furthermore, peptide immunoreactivity is reduced/lost in most other regions of the ventral cord in cases of ALS, while the dense peptidergic innervation of the VLN is spared (Gibson et al., 1988; Katagiri et al., 1988). It has therefore been speculated that the peptidergic input to this nucleus might contribute to the maintenance of motoneuron integrity.

Another property of the mentioned sacral motor nuclei is the sexual dimorphism that has been described in the rat. Thus, it has been shown that VLN (Jordan et al., 1982; McKenna and Nadelhaft, 1986) and VMN (Breedlove and Arnold, 1980, 1981; McKenna and Nadelhaft, 1986) motoneurons are both larger and more numerous in male rats when compared to females. Interestingly, no such sex differences have been encountered in the nearby located somatic (retro-) dorsolateral motor nucleus (Jordan et al., 1982; McKenna and Nadelhaft, 1986) that supplies the intrinsic muscles of the sole of the foot (e.g. Romanes, 1951; Ulfhake and Kellerth, 1983). The sex differences in the VLN and VMN arise during early development and are androgen dependent (Jordan et al., 1982; Breedlove and Arnold, 1983a,b). Androgens are furthermore believed to be critical for the maintenance of the synaptic inputs to the VMN motoneurons in adult male rats (Matsumoto et al., 1988).

As far as we know, no systematic ultrastructural study of the peptidergic innervation of the VLN has been done in the cat. This study was therefore initiated to obtain information on the distribution and synaptic arrangement of TRH-, SP-, and ENK-immunoreactive (IR) axonal boutons with the bundled dendrites of the VLN. The data obtained was also compared with similar observations of GABA-IR boutons (Ramírez-León and Ulfhake, 1993). Some of the results have been published in abstract form (Ramirez-León et al., 1993).

\section{Materials and methods}

Three adult female cats (body wt. $3 \mathrm{~kg}$ ) were anesthetized with pentobarbitone-sodium $(35-40 \mathrm{mg} / \mathrm{kg}$ body wt.) i.p. and perfused through the descending aorta with calcium-free Tyrode's buffer at $35^{\circ} \mathrm{C}$, followed by either a fixative mixture containing $4 \%$ paraformaldehyde, $0.2 \%$ (SP, TRH) or $0.5 \%$ (ENK) glutaraldehyde and $0.2 \%$ picric acid (Ulfhake et al., 1987a) dissolved in $0.1 \mathrm{M}$ phosphate-buffered saline (PBS) or $2 \%$ glutaraldehyde alone in $0.1 \mathrm{M}$ PBS (SP, TRH; Ulfhake et al., 1987b). After the perfusion the spinal lumbosacral segments were quickly removed and placed in fresh fixative.

The spinal cord tissue was processed for the peroxidase-antiperoxidase (PAP) method (Sternberger et al., 1970), essentially following the protocols of Steinbusch et al. (1978). After repeated rinses in 0.1 M PBS, the tissue blocks were placed in $5 \%$ sucrose buffer at $4^{\circ} \mathrm{C}$ until they sank. They were then cut in a series of $40-\mu \mathrm{m}$ thick transverse sections on a Vibratome (Oxford Lab., USA). The vibratome sections were treated with $1 \%$ sodium borohydride for $30 \mathrm{~min}$ (Willingham, 1983), and rinsed in 0.1 M PBS, followed by $0.05 \mathrm{M}$ tris-buffered saline (TBS). The sections were then incubated with primary antisera (see Table 1) at room temperature on a shaking table as follows: wash $10 \mathrm{~min} \times 3$ in TBS; $1 \%$ normal serum in TBS for $30 \mathrm{~min}$; primary antiserum against TRH, SP or ENK diluted in $0.05 \mathrm{M}$ BS (see Table 1) for $12 \mathrm{~h}$; wash $10 \mathrm{~min} \times 3$ in $0.05 \mathrm{M}$ TBS; bridge-antibody (goat anti-rabbit, rabbit anti-rat or rabbit anti-mouse; Dakopatts, Copenhagen, Denmark) diluted $1: 40$ or $1: 60$, for $2 \mathrm{~h}$; wash $10 \mathrm{~min} \times 3$ in TBS; PAP-antibody complex (rabbit, rat or mouse PAP complex; Dakopatts, Copenhagen, Denmark) diluted 1:400 or 1:600, for $1 \mathrm{~h}$; wash $10 \mathrm{~min} \times 2$ in TBS followed by $10 \mathrm{~min}$ in $0.05 \mathrm{M}$ Tris- $\mathrm{HCl}$; reaction with diaminobenzidine (Sigma, St. Louis, MO, USA) dissolved in $0.05 \mathrm{M}$ Tris- $\mathrm{HCl}(50 \mathrm{mg} / 100 \mathrm{ml})$ and $0.3 \% \mathrm{H}_{2} \mathrm{O}_{2}$. The reaction process was checked in the light microscope and stopped by transferring the sections to $0.05 \mathrm{M}$ Tris $-\mathrm{HCl}$. After 
Table 1

Antisera used in this study

\begin{tabular}{llllll}
\hline Antigen & Specification & Dilution & Raised in & Reference & Absorption test \\
\hline ENK & Leu-ENK; NOCl (mono- & & & & \\
& clonal) & $1: 100$ & Mouse & Cuello et al., 1984 & Arvidsson et al., 1992 \\
SP & NCI/34 (monoclonal) & $1: 200$ & Rat & Cuello et al., 1979 Arvidsson et al., 1990 & Visser et al., 1978 \\
TRH & 4319 (polyclonal) & $1: 1000-2000$ & Rabbit & Arvidsson et al., 1990 \\
\hline
\end{tabular}

repeated rinses in buffer the sections were transferred to Marchi's osmium solution, dehydrated in a graded series of acetone or ethanol, and embedded in Epon (= Agar 100 resin; Agar Aids, Essex, England; SP, TRH) or Durcupan ACM (Fluka Chemie AG, Buchs, Switzerland; ENK) between plastic foils. The sections incubated with antiserum against ENK were immersed in a solution of $2 \%$ glutaraldehyde in PBS for $1 \mathrm{~h}$ between the rinses in PBS and the Marchi staining, in order to improve the fine structure preservation.

The antisera used here have been characterized in previous studies, showing their selectivity in staining for TRH-, SP- or ENK-like immunoreactivity (LI), respectively. Thus, radioimmunoassay showed no crossreactivity for the antiserum against SP with brain peptides such as $\beta$-endorphin, leu-enkephalin, metenkephalin or somatostatin (Cuello et al., 1979), nor did the antiserum against ENK cross-react with a number of investigated peptides ( $\beta$-endorphin, dynorphin, vasoactive intestinal peptide, bombesin, angiotensin ${ }_{\mathrm{II}}$, neurotensin, bradykinin and somatostatin; see Cuello et al., 1984). The TRH-antiserum was shown to bind more selectively to the antigen against which it was raised, than to several TRH derivatives (Visser et al., 1978). According to control experiments, there was a complete absence of immunostaining after preabsorption of the antisera with an excess of the respective antigen (tested according to Wessendorf and Elde, 1985; see Arvidsson et al., 1990 for SP and TRH test results, and Arvidsson et al., 1992 for ENK test results). Finally, control sections incubated according to the PAP protocol described above, but omitting the respective primary antisera, were completely devoid of specific immunostaining. It can, however, not be completely ruled out that a hitherto unrecognized peptide possessing an epitope to which the antiserum cross-reacts, is present in the studied tissue.

Two vibratome sections for each immunoreactivity were re-embedded in Epon (SP, TRH) or Durcupan ACM (ENK), trimmed down and cut in series of ultrathin sections on an ultramicrotome (LKB, Stockholm, Sweden), mounted on alternating one-hole formvarcoated copper grids or nickel mesh grids and counterstained with uranyl acetate and lead citrate. As mentioned in earlier studies, there was a general decrease in staining intensity with increasing depth of the tissue sections (see e.g. Priestley and Cuello, 1983; Ulfhake et al., 1987a). Since the main aim of this study was to obtain information on the synaptic arrangement of IR axonal boutons with the bundled dendrites of the VLN, the selected vibratome sections for electron microscopy were those that could provide the best fine structure and had a high specific-to-background signal ratio. Normally these sections contained a fewer number of IR profiles, but also in such sections labeled profiles were still encountered at some depth $(\sim 10-15 \mu \mathrm{m})$.

The ultrathin sections were analyzed and photographed in a 301 or CM12 Philips electron microscope. To identify synaptic complexes, IR axonal boutons were traced from end to end through serial consecutive sections. In most cases, each bouton profile was photographed on each or every second section. The crosssectional area of the postsynaptic elements (i.e. dendrites) was measured directly from the micrographs (final magnification $\times 21,624)$ using a digitizing tablet (Summagraphic $^{\mathrm{TM}}$ ) and a Bioquant ${ }^{\mathrm{TM}}$ image analysis system (R\&M Biometrics, Inc., Nashville, TN, USA). From these data the equivalent dendritic diameters $(=2$ $\times$ (sq.root(area $/ \pi))$ ) were calculated in order to arrange the postsynaptic dendrites into diameter bins and estimate the distribution of the studied peptides within the dendritic trees of the VLN. Only dendrites cut perpendicularly, i.e. those with a rostro-caudal orientation, were subjected to analysis. This was determined by inspection of the neurotubuli profiles that appeared as elongated rather than circular or near-circular, if not cut at a right angle. Dendrites that extend into the ventrolateral bundle (VLB) deriving from other adjacent neuronal groups (see also Discussion) will in most cases have an oblique or transverse path.

Statistical analyses included Kruskal-Wallis analysis of variance for multiple groups, Mann-Whitney twosample test ( $U$-test) and contingency table analysis of bin data. The level of significance was set at $P<0.05$.

The use of cats and the performed experiments for the purpose of this study were approved by the Local Ethical Committee (i.e., Stockholms Norra Djurförsöksetiska Nämnd; project N27/90).

\section{Results}

Fig. 1A shows the general appearance of the VLN. The neuropil is completely dominated by the occurrence of rostro-caudally oriented dendrites, forming the VLB. 
Also neuronal cell bodies in the $\alpha$-motoneuron sizerange, presumed to be the parent motoneurons of the bundled dendrites, can be seen.

The equivalent dendritic diameter (see Materials and methods) of a reference sample of 358 rostro-caudally oriented dendrites deriving from a randomly selected cross-section through the VLN region of the spinal cord, was compared with the calibre values of a larger material that comprised dendritic branches $(n=1906)$ belonging to gastrocnemius $\alpha$-motoneurons (data replotted from Burke et al., 1992). As can be seen in the histogram of Fig. 2A, the distribution of dendrites is rather similar in the two materials $(P=0.20 ; U$-test of the original data sets). Furthermore, since the gastrocnemius materi-
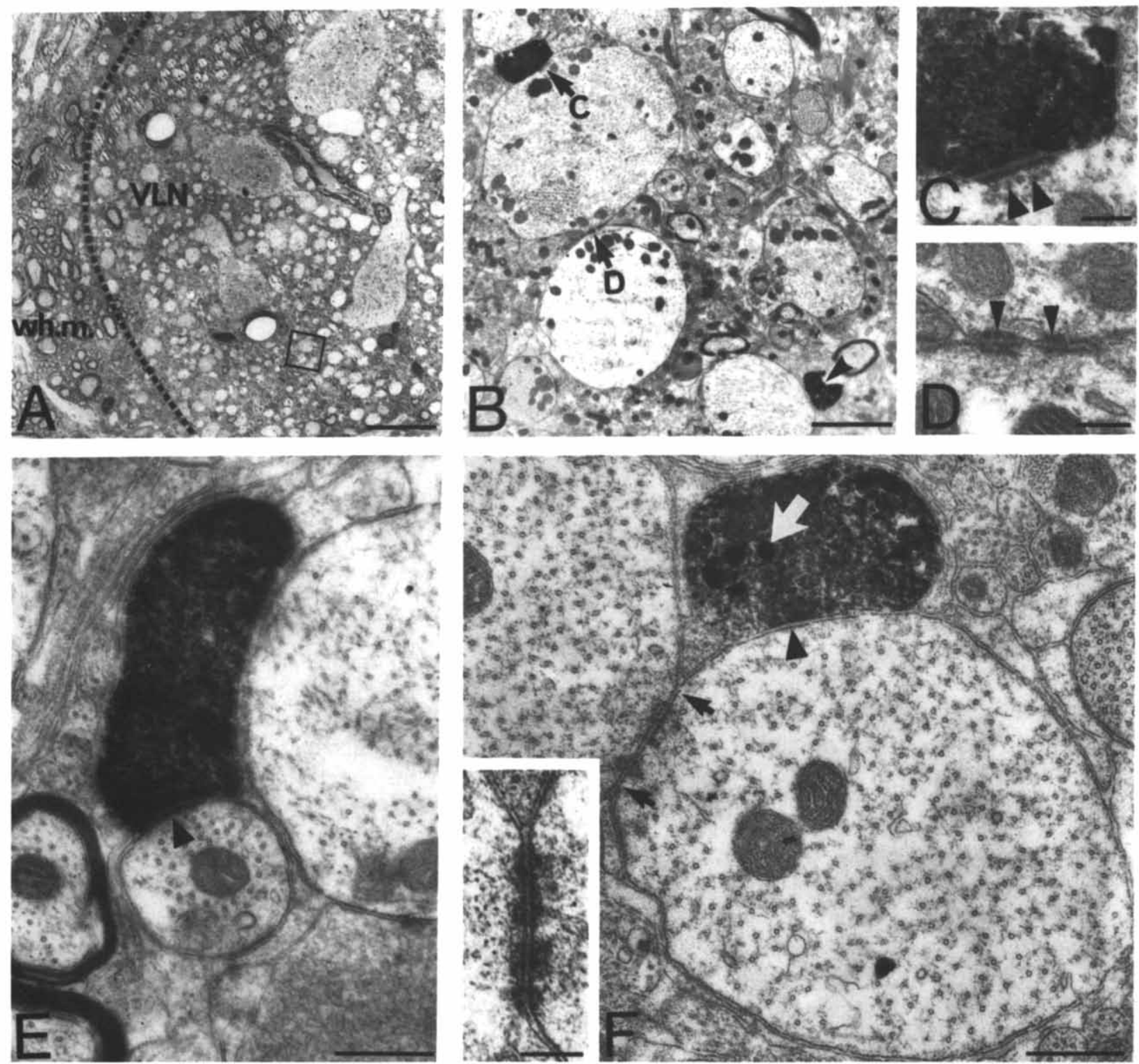

Fig. 1. Electron micrographs of TRH-IR boutons in the VLN. (A) Low-power micrograph showing an overview of the VLN. The neuropil is dominated by the occurrence of bundled dendrites and large neuronal cell bodies. Dotted line indicates the border between white $(=$ wh.m. $)$ and grey matter. (B) Micrograph from an ultrathin section adjacent to the one in (A), illustrating the framed region at higher magnification. Here, two TRH-IR profiles (arrow C, arrowhead) can be seen. One of them forms a synaptic junction (arrow C) with a medium-calibre dendrite participating in a dendro-dendritic contact (arrow D). (C,D) High-power micrographs of the axo-dendritic synaptic complex (C) and the dendro-dendritic contact site (D; arrowheads). In (C), arrowheads point at Taxi bodies located subsynaptically. (E) One of the few TRH-IR boutons that is in synaptic contact (arrowhead) with a fine-calibre dendrite. (F) A TRH-IR bouton forming a synaptic junction (arrowhead) with a dendrite that participates in a dendro-dendritic contact (the extent of the apposition is indicated by arrows). Note the intense PAP-labeling of large dense core vesicles (white arrow). The dendro-dendritic junctional complex is shown at higher magnification in the inset micrograph. Note the juxta-junctional accumulation of electron dense material. Scale bars: (A) $20 \mu \mathrm{m}$; (B) $2 \mu \mathrm{m}$; (C-F) $0.5 \mu \mathrm{m}$; inset (F) $0.2 \mu \mathrm{m}$. 

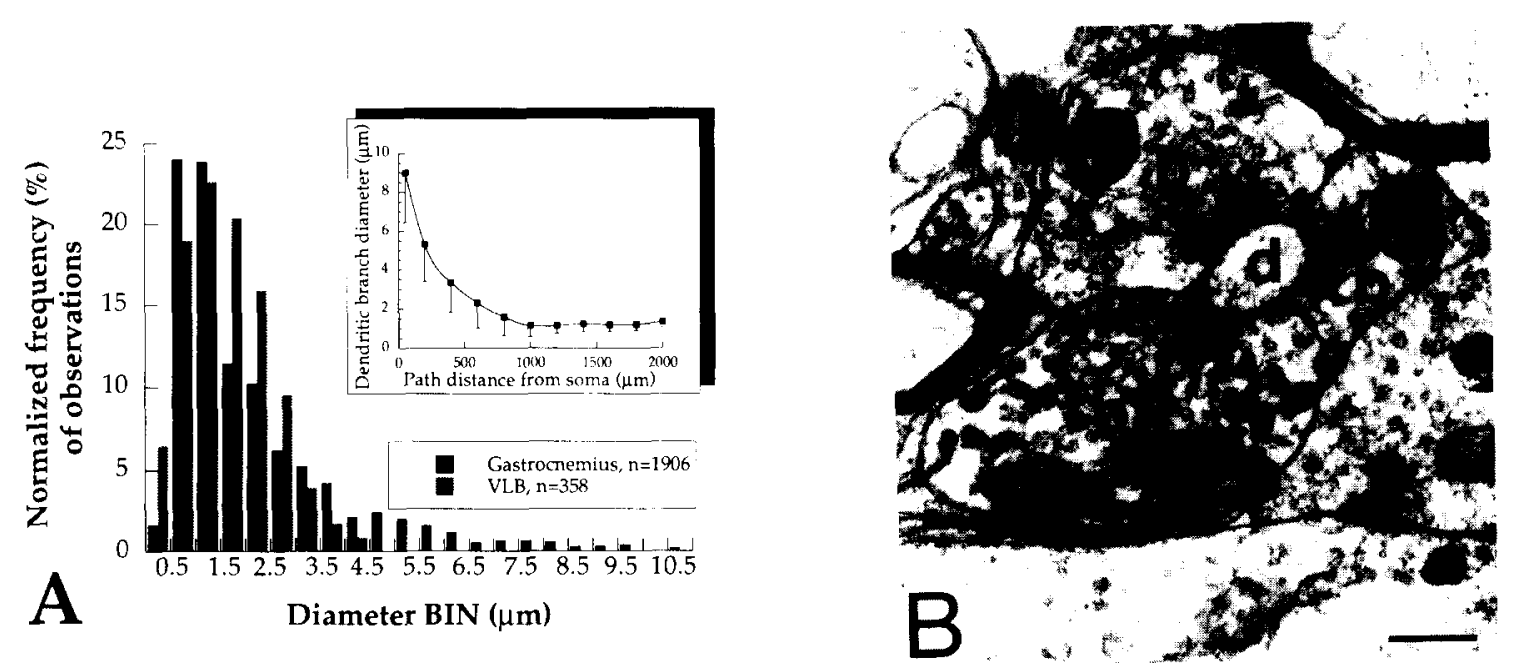

Fig. 2. (A) Histogram showing the normalized frequency distribution of dendritic branches into different diameter bins for two reference materials; VLB dendrites (grey) and gastrocnemius motoneuron dendrites (black; data replotted from Burke et al., 1992). Vertical bars represent the frequency values for each diameter bin, and the upper limit diameter value separating bins has been indicated on the abscissa. Inset shows the relationship between dendritic branch diameter and proximo-distal path distance from the cell soma for the gastrocnemius material (data replotted from Burke et al., 1992). Average values and S.D. have been indicated. (B) Electron micrograph of a fine-calibre dendrite (= d) in synaptic contact with three unlabeled boutons $(b=$ bouton), illustrating that also the finest dendritic branches receive synaptic input. Scale bar: $0.5 \mu \mathrm{m}$.

al derives from complete reconstructions of physiologically identified $\alpha$-motoneurons intracellularly labeled with horseradish peroxidase, it does not include any sampling bias for fine-, medium- or large-calibre dendritic branches.

\section{I. TRH-IR axonal boutons}

Thirty-four TRH-IR boutons with identified synaptic complexes were traced in series of consecutive sections. The postsynaptic element was always a dendrite, with a diameter of, on average, $3.2 \mu \mathrm{m}( \pm 1.4 \mu \mathrm{m} \mathrm{S.D}$. $)$. The diameter range of the postsynaptic dendrites $(0.9-7.1$ $\mu \mathrm{m})$ indicated that TRH-IR boutons may contact both thick proximal dendrites (Figs. $1 \mathrm{~B}, \mathrm{C}, \mathrm{F}$ ) and thin distal branches (Fig. 1E). Dendrites postsynaptic to TRH-IR boutons were often involved in dendro-dendritic contacts of desmosomal or puncta adherentia type (Figs. IB,D,F). In addition, some vesicle-containing TRH-IR axonal varicosities that were traced in series appeared to be devoid of synaptic specializations and seemed to be separated from nearby neuronal elements by thin glial processes (not shown).

The fine structure of TRH-IR boutons in the VLN was similar to that previously described in the $\mathrm{L} 7$ motor nucleus of the cat (Ulfhake et al., 1987a) and coincided also in general with that reported here for SP-IR boutons (see Fig. 3B and also below). Thus, TRH-IR boutons contained mainly small agranular vesicles, apparently of spherical or pleomorphic type, and a vary- ing number of intensely labeled large granular (dense core) vesicles (Fig. 1F). Taxi bodies could sometimes be encountered subsynaptically (Fig. 1C).

\subsection{SP-IR axonal boutons}

Twenty-six SP-IR boutons disclosing clear synaptic specializations were traced in series. They were seen in synaptic contact with bundled dendrites that had, on average, a diameter of $2.9 \mu \mathrm{m}( \pm 2.2 \mu \mathrm{m}$ S.D.; range $0.9-10.6 \mu \mathrm{m}$ ). Thus, both small- (Fig. 3A) and largecalibre dendrites (not shown) receive $S P$ input. An interesting feature, not observed among TRH-IR boutons, was that one and the same SP-IR bouton could be found in synaptic contact with two adjacent dendrites (Figs. 3C,D). Vesicle-containing IR axonal varicosities that appeared devoid of synaptic specializations were also found in the SP material (not shown).

The PAP labeling pattern of SP-IR boutons did not differ from that of TRH-IR boutons. Synaptic vesicles were either of the small agranular or large granular (dense core) type (Fig. 3B). The vast majority of the IR boutons were heavily labeled with PAP reaction product, which impeded a detailed analysis of vesicle shape. In lightly stained boutons (see e.g. Fig. 3B) the shape of agranular vesicles appeared, however, to be spherical or pleomorphic.

\subsection{ENK-IR axonal boutons}

Twenty-nine ENK-IR boutons were traced through the section series and all of them were in synaptic con- 

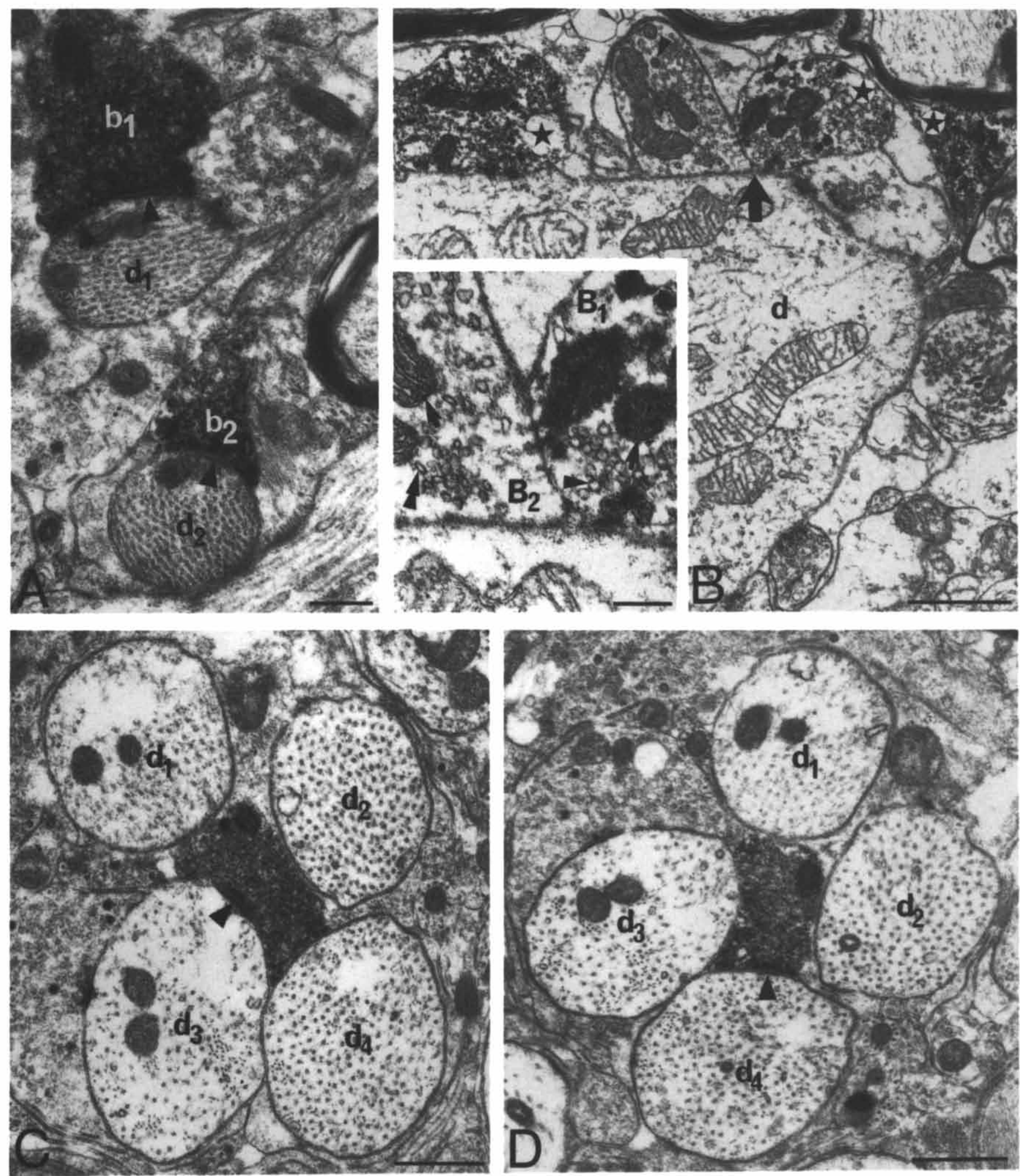

Fig. 3. Electron micrographs of SP-IR boutons in the VLN. (A) Two SP-IR boutons $\left(b_{1}, b_{2}\right)$, each of them forming a synaptic junction (arrowheads) with a fine-calibre dendrite $\left(d_{1}, d_{2}\right)$. (B) SP-IR boutons (stars), two of them in close apposition with a longitudinally sectioned proximal dendrite (d). The region indicated by a big arrow is seen at higher magnification in the inset micrograph. The mitochondria (arrows in inset) and dense core vesicles (arrowheads in $(B)$ ) of the labeled bouton $\left(B_{1}\right)$ are coated with PAP reaction product, which is to be compared with the ones of the adjacent unlabeled bouton $\left(B_{2}\right)$. Note also the spherical shape of the agranular vesicles in $\mathbf{B}_{1}$ (arrowhead in inset) compared to the flat vesicles (double arrowheads in inset) seen in $B_{2}$. (C,D) Selected micrographs from a series of ultrathin sections through an SP-IR bouton that is in synaptic contact (arrowheads) with two adjacent dendrites, $d_{3}$ and $d_{4}$. Scale bars: (A) $0.5 \mu \mathrm{m}$; (B-D) $1 \mu \mathrm{m}$; inset (B) $0.2 \mu \mathrm{m}$. 
tact with bundled dendrites (Figs. 4A-D). The diameter of the postsynaptic elements was on average $2.7 \mu \mathrm{m}( \pm$ $1.1 \mu \mathrm{m}$ S.D.; range 1.1-5.3 $\mu \mathrm{m}$ ). A difference between ENK-IR boutons and those IR to TRH or SP, was that non-synaptic ENK-IR profiles were not seen. As in the SP material, one and the same ENK-IR bouton could be found in synaptic contact with two adjacent dendrites (Figs. 4A,C,D). The postsynaptic dendrites involved in such arrangements were often coupled to each other by dendro-dendritic contacts (Figs. 4A,C,D).

The PAP labeling characteristics were identical to those of the TRH and SP materials; ENK-IR boutons contained thus both small agranular and large dense core vesicles. The former vesicles appeared to be spherical in shape (Figs. 3B,C), which agrees with the results from a previous ultrastructural study of the cat sacral parasympathetic ganglia (Kawatani et al., 1989).

\subsection{Distribution of IR boutons within the dendritic arborizations}

As has been previously shown (e.g. Ulfhake and Kellerth, 1981), dendritic diameter declines with increasing path distance from the cell soma (see also inset to Fig. 2A), due to both calibre decrease across branching
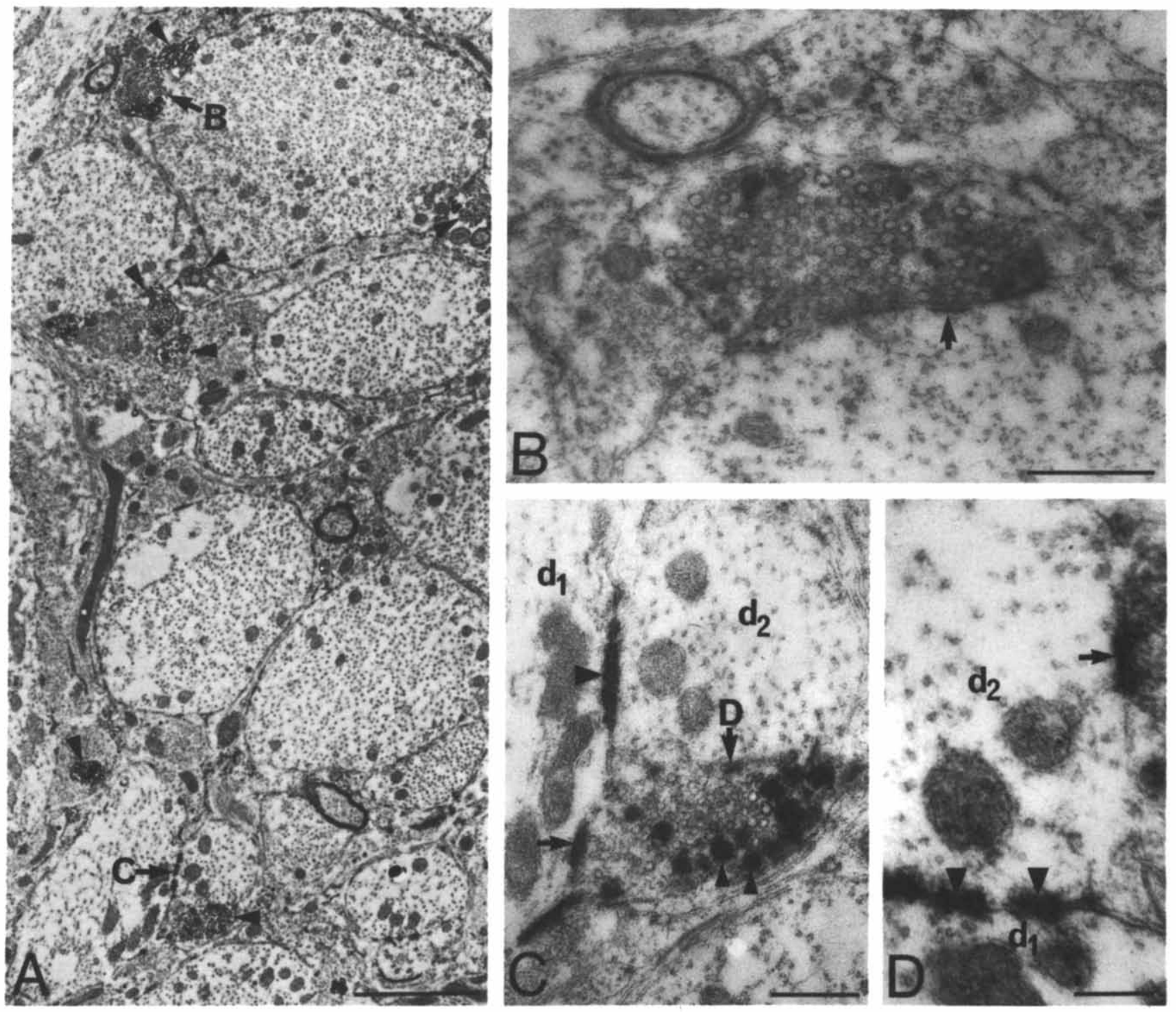

Fig. 4. Electron micrographs of ENK-IR boutons in the VLN. (A) Low-power micrograph of a region in the VLN, where several ENK-IR boutons (arrowheads) can be seen in the vicinity of bundled dendrites. (B) Micrograph from an ultrathin section adjacent to the one in (A) (see arrow B). showing an ENK-IR bouton in synaptic contact (arrow) with a medium-calibre dendrite. Note the spherical shape of the synaptic vesicles. (C.D) Micrographs from ultrathin sections adjacent to the one in (A) (see arrow C). An ENK-IR bouton is seen forming synaptic junctions (arrows in (C) and (D)) with two dendrites $\left(\mathrm{d}_{1}, \mathrm{~d}_{2}\right)$ that are coupled to each other. Big arrowheads in (C) and (D) point to the dendro-dendritic contact site. Small arrowheads in (C) indicate the presence of dense core vesicles in the labeled bouton. Scale bars: (A) $2 \mu \mathrm{m}$; (B-C) $0.5 \mu \mathrm{m}$; (D) $0.2 \mu \mathrm{m}$. 

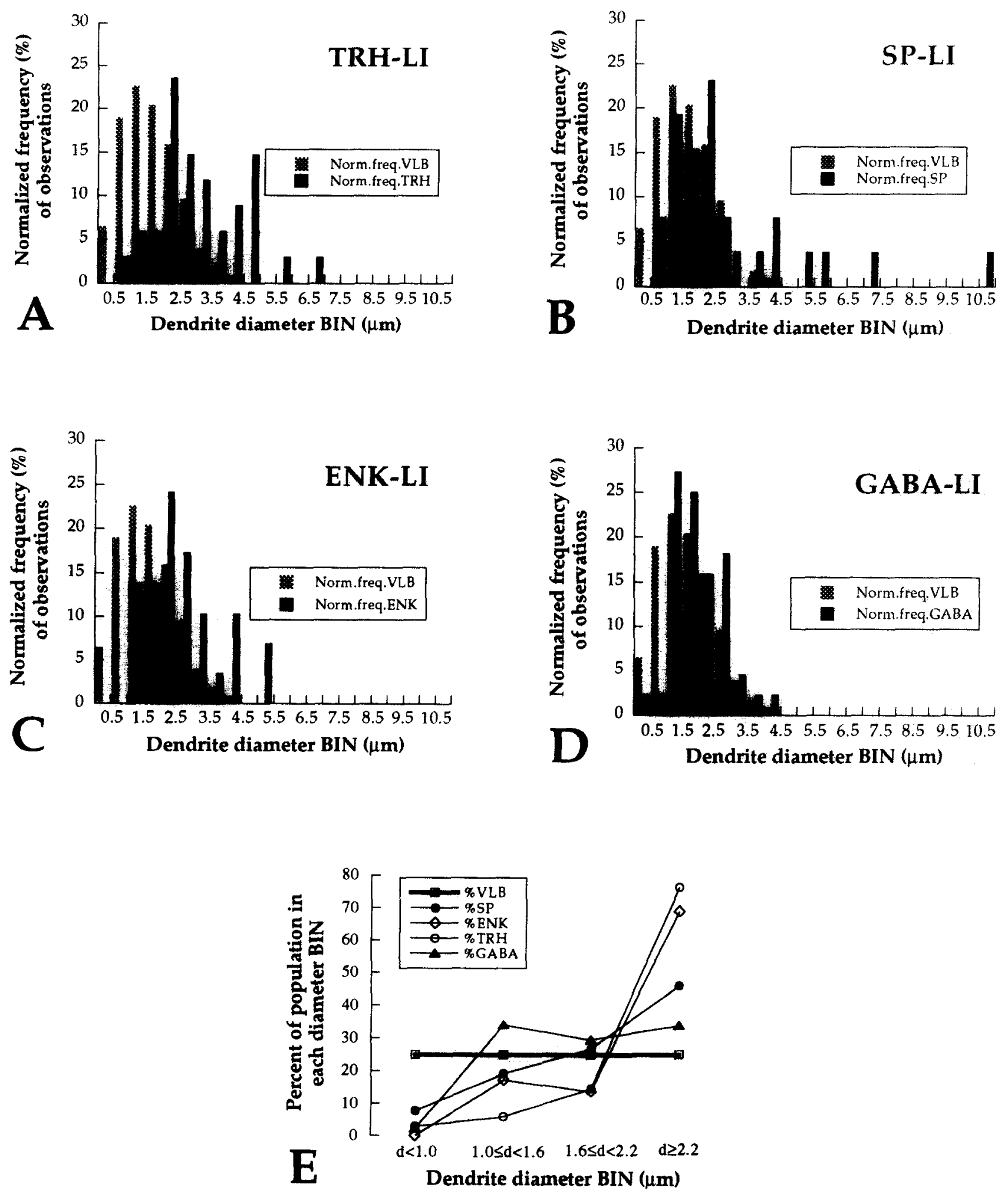

Fig. 5. (A-D) Histograms illustrating the normalized frequency distribution of the diameter of bundled dendrites (black vertical bars) postsynaptic to boutons IR to (A) TRH, (B) SP, (C) ENK or (D) GABA (data replotted from Ramírez-León and Ulfhake, 1993), respectively. Vertical bars represent the frequency values for each diameter bin, and the upper limit diameter value separating bins has been indicated on the abscissa. The data sets have been compared with a reference material of VLB dendrites (grey vertical bars; see also Fig. 2A). (E) In this diagram the VLB reference sample has been arranged into 4 bins, each of them comprising about the same number of observations, i.e. $\sim 25 \%$. The data sets of dendrites postsynaptic to the respective immunoreactivities were arranged accordingly, in order to allow comparison and statistical tests (for details, see text). 
points and calibre tapering between branching nodes. The probability of encountering thick dendrites is therefore higher close to the cell body, while the reverse is true for fine-calibre dendrites. Thus, the proximodistal location of synaptic inputs within the dendritic trees can be inferred from the size of the postsynaptic dendrites. The current data sets obtained from ENK, SP and TRH immunostaining were therefore plotted against the reference sample of VLB dendrites described above (see Fig. 2A), in order to judge if the distribution of the respective synaptic inputs was biased towards proximal or distal dendritic branches (see Fig. 5). For comparison, a data set of GABA-IR boutons innervating the bundled dendrites of the VLN (data replotted from Ramírez-León and Ulfhake, 1993) was also included.

In the histograms of Fig. 5 it can be seen that only SPIR boutons displayed a frequency distribution indicating that this input is rather evenly distributed across the dendritic trees of the VLN. The other three messenger substances showed an only marginal (TRH, GABA) or no input at all (ENK) on fine-calibre branches. Analysis of variance revealed a statistically significant variance between the original data sets of dendrites (Kruskal-Wallis; $P<0.001$ ). In order to study this further, the reference sample of VLB dendrites was divided into 4 diameter bins $(<0.98 \mu \mathrm{m}, n=89 ; 0.98-1.57 \mu \mathrm{m}$, $n=90 ; 1.58-2.17, n=89 ;>2.17 \mu \mathrm{m}, n=90$ ), with each bin comprising about the same number of observations. The 4 groups of dendrites postsynaptic to the different immunoreactivities were then arranged into the same diameter bins as the VLB sample (see Fig. 5E) and subjected to contingency table analysis. Chi-square statistics revealed that the distribution of both ENKand TRH-IR boutons displayed a highly significant deviation $(P<0.001)$ from the distribution of the reference sample, with a marked skewness towards thicker dendrites. Also the distribution of GABA-IR boutons differed from that of the VLB sample $(P<0.01)$, while the population of dendrites postsynaptic to SP-IR boutons did not disclose a corresponding statistically significant difference $(P=0.06)$.

\section{Discussion}

4.1. Origin and spatial distribution of TRH-, SP- and ENK-IR synaptic boutons in the VLN

The motoneurons supplying the sphincter urethrae, the sphincter ani externus and the ischiocavernosii muscles are the main neuronal components of the VLN (e.g. Sato et al., 1978; Kuzuhara et al., 1980; Schrøder, 1980; McKenna and Nadelhaft, 1986). Anatomical studies have shown that these motoneurons are the source of origin for the dendrites in the rostro-caudally oriented VLB (see e.g. Roney et al., 1979; Bellinger and Ander- son, 1987). Dendritic profiles included in this study were all confined to the VLB region and had a rostro-caudal orientation. Thus, it is most likely that the vast majority derived from VLN motoneurons, although an interneuronal origin can not be completely excluded for a minor portion of the dendrites. Dendrites extending into the VLN from adjacent nuclei in the ventral horn will in most cases have a radial or transverse orientation (see e.g. Ulfhake and Kellerth, 1983) and have thus been excluded from the dendritic profiles analyzed here.

The current study shows that there are differences in the spatial distribution of ENK, SP and TRH inputs to the VLN motoneurons. It is of interest in this context that these messenger substances also differ from each other with respect to their origin(s). Thus, TRH-IR boutons in the spinal cord motor nuclei have been shown to derive exclusively from supraspinal levels (Hökfelt et al., 1980; Johansson et al., 1981; Gilbert et al., 1982; Arvidsson et al., 1990), and this seems also to be the case in the VLN (Ramírez-León et al., 1994). Furthermore, it has been reported that most, if not all, immunoreactive TRH in the motor nuclei is confined to axonal fibers of the serotoninergic bulbospinal system (Johansson et al., 1981; Arvidsson et al., 1990). The vast majority, if not all, of the here studied TRH-IR axonal boutons belong therefore with all probability to this system. TRH-IR boutons had a preferential distribution to medium-to-large dendrites, indicating a proximal allocation within the dendritic trees of VLN motoneurons (Fig. 6A). In comparison, SP-IR boutons were encountered impinging on dendrites of all calibre sizes and with a frequency distribution indicating a more even allocation throughout the dendritic trees than the other immunoreactivities studied here (Fig. 6A). SP immunoreactivity is found in primary afferents and neurons intrinsic to the spinal cord (Hökfelt et al., 1975; Ljungdahl et al., 1978; Tessler et al., 1980, 1981), as well as in a substantial number of the descending 5-HT-IR fibers in the ventral horn motor nuclei (Hökfelt et al., 1978; Johansson et al., 1981; Gilbert et al., 1982; Tashiro and Ruda, 1988; Arvidsson et al., 1990). This seems also to be the case in the VLN of the rat (Micevych et al., 1986) and cat (Erdman et al., 1984; Tashiro et al., 1989b; Ramírez-León et al., 1994). It may then be that in the VLN the SP-IR boutons in synaptic contact with thick stem dendrites and fine-calibre distal branches belong to circuitries intrinsic to the spinal cord, while those impinging on medium-to-large dendrites can be of either spinal or supraspinal origin (Fig. 6A). Many of the latter SP-IR boutons may belong to the descending 5-HT system also containing TRH-LI.

The descending 5-HT system (Dahlström and Fuxe, 1964) has a well-established facilitatory effect on the excitation of spinal motoneurons (White, 1985; for references see also Arvidsson et al., 1990). The role of the coexistent peptides TRH and SP in serotoninergic 

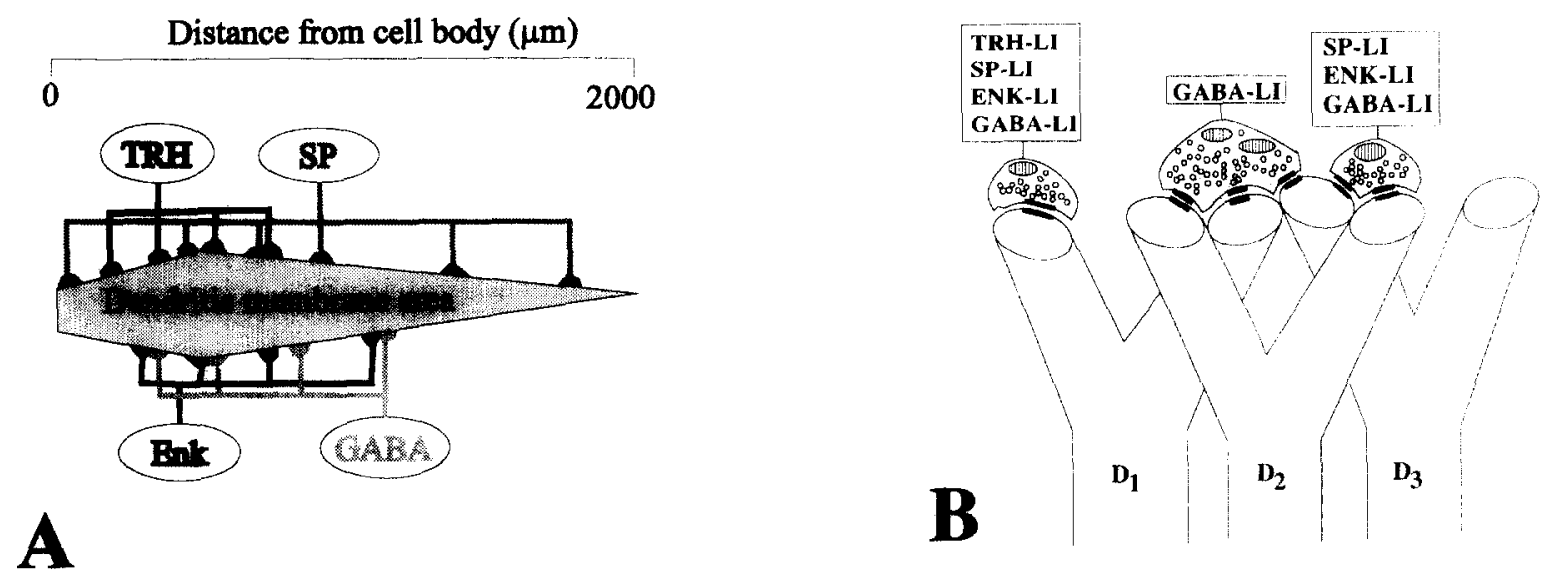

Fig. 6. (A) Schematic drawing of a VLN dendritic tree showing the spatial distribution of TRH, SP, ENK and GABA inputs. The area depicted represents the relative distribution of dendritic membrane area at different distances from the cell body. (B) Schematic drawing illustrating the synaptic arrangement of IR axonal boutons on bundled dendrites of the VLN. TRH-IR boutons are only seen in contact with a single postsynaptic element. SP- and ENK-IR boutons can also be found in synaptic contact with 2 dendrites, while one and the same GABA-IR bouton often is in synaptic contact with $2-3$ dendrites.

transmission is not fully understood, but TRH can depolarize motoneurons and is believed to enhance the facilitatory effect of 5-HT. It has been shown that SP has a similar effect, and available evidence indicates in addition that SP acts via presynaptic mechanisms at the 5-HT synapse. Interestingly, it has recently been shown that the 5-HT system may modulate the descending inhibition of spinal sexual reflexes (Marson and McKenna, 1992), exerting thus a direct action on pudendal motoneurons.

The VLN seems to have a denser network of ENK-IR axons when compared to other motor nuclei of the lumbosacral spinal cord (e.g. Glazer and Basbaum, 1980; Hunt et al., 1981; Romagnano and Hamill, 1985; Katagiri et al., 1986) such as, for example, the nearby located (retro-) dorsolateral motor nucleus that supplies the intrinsic muscles of the sole of the foot (Romanes, 1951; Ulfhake and Kellerth, 1983). The ENKergic distribution is furthermore rather similar to that seen in the sacral parasympathetic nucleus (SPN; e.g. de Groat et al., 1983; Romagnano and Hamill, 1985; Katagiri et al., 1986; Gibson et al., 1988). Thus, the dense ENK-IR innervation of the SPN and VLN may indicate a parallel organization of the synaptic input, co-ordinating somatic and parasympathetic reflex circuitries in these regions.

Although it has been observed that cell bodies in the raphé nuclei of the medulla oblongata stain for both 5HT- and ENK-LI (Glazer et al., 1981; Hunt and Lovick, 1982; Léger et al., 1986; Millhorn et al., 1989), double and triple labeling studies have failed to demonstrate a corresponding degree of coexistence between 5-HT- and ENK-LI in the ventral horn motor nuclei (Tashiro et al., 1988; Wessendorf et al., 1990). Furthermore, no major changes have been reported in the density of ENK-IR axons in the VLN following spinal cord transection (e.g. Erdman et al., 1984; Konishi et al., 1985; Micevych et al., 1986; Romagnano et al., 1987; Tashiro et al., 1989b; Ramírez-león et al., 1994), indicating that the main source of origin for the ENK input to this nucleus is spinal. In this study, ENK-IR synaptic boutons were encountered exclusively on medium-to-large dendrites (Fig. 6A). Thus, ENK-LI does not seem to be associated with peripheral input(s) to the dendritic trees of the VLN. ENK has an inhibitory effect on spinal motoneurons (e.g. Zieglgänsberger and Tulloch, 1979; Suzuki et al., 1986) as well as on both central and ganglionic synapses of the visceral parasympathetic reflex pathways (de Groat et al., 1983). Whether this inhibitory action also is valid for VLN motoneurons remains to be elucidated. It is, however, of interest in this context that GABA, a well-established inhibitory neurotransmitter (for review, see Rudomin, 1990) of mainly spinal origin (e.g. Tappaz et al., 1976; Barber et al., 1982), has a distribution to the VLN motoneuron dendrites similar to that of ENK (Ramírez-León and Ulfhake, 1993). However, an extensive GABAergic input to the cell bodies in the VLN is also present (Ramirez-León and Ulfhake, 1993), which was not observed among the ENK-IR boutons in the material studied here.

Fine-calibre dendrites $(<1 \mu \mathrm{m}$ ) represent about $25 \%$ of the dendritic branches in the VLB, but receive, with the exception of SP $(8 \%)$, very little $(<3 \%)$ peptidergic or GABAergic input, although the degree of dendritic membrane covering by bouton profiles in the VLN does not seem to vary much with the calibre of the postsynaptic dendrite (Ramírez-León and Ulfhake, 1993; see also Fig. 2B in this study). 
4.2. Synaptic arrangement of the peptidergic and GABAergic input to the $V L N$

It has been shown in the VLN that one and the same axonal bouton can establish synaptic contact with several adjacent dendrites (see e.g. Kerns and Peters, 1974; Konishi et al., 1978). This is a common feature of the GABAergic input to the VLN, where one GABA-IR bouton can be found in contact with 2-3 dendrites (Ramírez-León and Ulfhake, 1993). In addition, the postsynaptic dendrites involved are often coupled to each other through dendro-dendritic contacts of desmosomal or puncta adherentia type. In this study we also show that both SP- and ENK-IR boutons often are engaged in dual contacts with dendrites, although such contacts were not as frequent as in the GABA material. Interestingly, a similar arrangement was not observed for TRH-IR boutons. According to morphological studies, axons frequently form en passant synaptic junctions irrespective of the transmitter content of the axon terminals involved, and this arrangement may be a means for single axons to diverge to several postsynaptic targets. Both light and electron microscopic studies of the 5-HT bulbospinal pathway (e.g. Fuxe, 1965; Ulfhake et al., 1987a; Arvidsson et al., 1990) have shown that en passant type of boutons is very common in this system. In this study, it is shown that spinal inputs to the VLN also display another type of divergence at the terminal level, while the supraspinal input to the VLN seems rather to be a point-to-point system with each axonal bouton acting on a single postsynaptic element (Fig. $6 \mathrm{~B})$. A possible role for the divergence at the terminal level may be to further enhance synchronized activation/deactivation of VLN motoneurons that participate in viscero-somatic reflexes such as those resulting in micturition, defecation and ejaculation.

Finally, a number of TRH- and SP-IR axonal varicosities that were traced through serial consecutive sections appeared to lack synaptic specialization and even direct membrane apposition with neuronal elements, a feature that has also been reported from the $\mathrm{L} 7$ motor nucleus of the cat (Ulfhake et al., 1987a). It is difficult, however, to judge the frequency of occurrence of non-synaptic axonal boutons in material as the one used in this study, since small synaptic specializations may have escaped detection due to the heavily labeling by PAP reaction product. Non-synaptic boutons may, however, represent a considerable fraction of the total number of boutons (see also Ulfhake et al., 1987a). Whether such axonal boutons liberate their messenger molecules into the extracellular space to act in a 'parasynaptic' mode through diffusion remains however to be elucidated.

\section{Acknowledgements}

This study was supported by grants from the Swedish Medical Research Council (projects no. 12X-10820 and
04X-2887), Stiftelsen R. \& E. Lundströms Minne, Svenska Sällskapet för Medicinsk Forskning, A.O. Swärds stiftelse, E. \& O. Ahréns stiftelse, L. \& H. Ostermans Fond and the Karolinska Institute.

\section{References}

Anderson, W.J., Stromberg, M.W. and Hinsman, E.J. (1976) Morphological characteristics of dendrite bundles in the lumbar spinal cord of the rat. Brain Res. 110, 215-227.

Appel, N.M., Wessendorf, M.W. and Elde, R.P. (1987) Thyrotropinreleasing hormone in spinal cord: coexistence with serotonin and with substance $P$ in fibers and terminals apposing identified preganglionic sympathetic neurons. Brain Res. 415, 137-143.

Arvidsson, U., Cullheim, S., Ulfhake, B.. Bennett, G.W., Fone, K.C.F., Cuello, A.C., Verhofstad, A.A.J., Visser, T.J. and Hökfelt, T. (1990) 5-hydroxytryptamine, substance $P$, and thyrotropinreleasing hormone in the adult cat spinal cord segment L7: immunohistochemical and chemical studies. Synapse 6, 237-270.

Arvidsson, U., Cullheim, S., Ulfhake, B., Ramirez, V., Dagerlind, A.. Luppi, P.-H., Kitahama, K., Jouvet, M., Terenius, L., Åman, K. and Hökfelt, T. (1992) Distribution of enkephalin and its relation to serotonin in cat and monkey spinal cord and brain stem. Synopse 11, 85-104.

Barber, R.P., Vaughn, J.E. and Roberts. E. (1982) The cytoarchitecture of GABAergic neurons in rat spinal cord. Brain Res. 238. $305-328$.

Bellinger, D.L. and Anderson, W.J. (1987) Postnatal development of cell columns and their associated dendritic bundles in the lumbosacral spinal cord of the rat. I. The ventrolateral cell column. Dev. Brain Res. 35, 55-67.

Breedlove, S.M. and Arnold, A.P. (1980) Hormone accumulation in a sexually dimorphic motor nucleus of the rat spinal cord. Science $210,564-566$.

Breedlove, S.M. and Arnold, A.P. (1981) Sexually dimorphic motor nucleus in the rat lumbar spinal cord: response to adult hormone manipulation, absence in androgen-insensitive rats. Brain Res. 225, 297-307.

Breedlove, S.M. and Arnold, A.P. (1983a) Hormonal control of a developing neuromuscular system. I. Complete demasculinization of the male rat spinal nucleus of the bulbocavernosus using the anti-androgen flutamide. J. Neurosei. 3, 417-423.

Breedlove, S.M. and Arnold, A.P. (1983b) Hormonal control of a developing neuromuscular system. II. Sensitive periods for the androgen-induced masculinization of the rat spinal nucleus of the bulbocavernosus. J. Neurosci. 3, 424-432.

Burke, R.E., Marks, W.B. and Ulfhake. B. (1992) A parsimonious description of motoneuron dendritic morphology using computer simulation. J. Neurosci. 12, 2403-2416.

Cuello, A.C.. Galfré, G. and Milstein. C. (1979) Detection of substance $\mathbf{P}$ in the central nervous system by a monoclonal antibody. Proc. Natl. Acad. Sci. USA 76, 3532-3536.

Cuello, A.C. Milstein, C.. Couture, R.. Wright, B.. Priestley, J.V. and Jarvis, J. (1984) Characterization and immunocytochemical application of monoclonal antibodies against enkephalins. $J$ Histochem. Cytochem. 32, 947-957.

Dahlström, A. and Fuxe, K. (1964) Evidence for the existence of monoamine-containing neurons in the central nervous system. I. Demonstration of monoamines in the cell bodies of brain stem neurons. Acta Physiol. Scand. 62 (Suppl. 232), 1-55.

de Groat, W.C., Kawatani, M., Hisamitsu. T., Lowe, I., Morgan. C., Roppolo. J.. Booth. A.M.. Nadelhaft, I.. Kuo, D. and Thor, K. (1983) The role of neuropeptides in the sacral autonomic reflex pathways of the cat. J. Auton. Nerv. Syst. 7, 339-350.

Dekker, J.J., Lawrence, D.G. and Kuypers, H.G.J.M. (1973) The location of longitudinally running dendrites in the ventral horn of the cat spinal cord. Brain Res. 51. 319-325. 
Erdman, S.L., Kawatani, M., Thor, K.B., Eskay, R. and de Groat, W.C. (1984) Identification of neuropeptides in Onuf's nucleus in the cat. Soc. Neurosci. Abstr. 10 (1), 432.

Fuxe, K. (1965) Evidence for the existence of monoamine neurons in the central nervous system. III. The monoamine nerve terminal. $Z$. Zellforsch. 65, 573-596.

Gibson, S.J., Polak, J.M., Katagiri, T., Su, H., Weller, R.O., Brownell, D.B., Holland, S., Hughes, J.T., Kikuyama, S., Ball, J., Bloom, S.R., Steiner, T.J., de Belleroche, J. and Clifford Rose, F. (1988) A comparison of the distributions of eight peptides in spinal cord from normal controls and cases of motor neurone disease with special reference to Onuf's nucleus. Brain Res. 474, 255-278.

Gilbert, R.F.T., Emson, P.C., Hunt, S.P., Bennett, G.W., Marsden, C.A., Sandberg, B.E.B., Steinbusch, H.W.M. and Verhofstad, A.A.J. (1982) The effects of monoamine neurotoxins on peptides in the rat spinal cord. Neuroscience 7, 69-87.

Glazer, E.J. and Basbaum, A.I. (1980) Leucine enkephalin: localization in and axoplasmic transport by sacral parasympathetic preganglionic neurons. Science 208, 1479-1481.

Glazer, E.J., Steinbusch, H., Verhofstad, A. and Basbaum, A.I. (1981) Serotonin neurons in nucleus raphe dorsalis and paragigantocellularis of the cat contain enkephalin. J. Physiol. (Paris) 77, 241-245.

Hökfelt, T., Kellerth, J.-O., Nilsson, G. and Pernow, B. (1975) Experimental immunohistochemical studies on the localization and distribution of substance $\mathrm{P}$ in cat primary sensory neurons. Brain Res. $100,235-252$.

Hökfelt, T., Ljungdahl, A., Steinbusch, H., Verhofstad, A., Nilsson, G., Brodin, E., Pernow, B. and Goldstein, M. (1978) Immunohistochemical evidence of substance-P-like immunoreactivity in some 5-hydroxytryptamine-containing neurons in the rat central nervous system. Neuroscience 3, 517-538.

Hökfelt, T., Lundberg, J.M., Schultzberg, M., Johansson, O., Ljungdahl, $\AA$. and Rehfeld, J. (1980) Coexistence of peptides and putative transmitters in neurons. In Neural Peptides and Neuronal Communication (eds Costa, E. and Trabucchi, M.), pp. 1-23. Raven Press, New York.

Hunt, S.P. and Lovick, T.A. (1982) The distribution of serotonin, metenkephalin and $\beta$-lipotropin-like immunoreactivity in neuronal perikarya of the cat brainstem. Neurosci. Lett. 30, 139-145.

Hunt, S.P., Emson, P.C., Gilbert, R., Goidstein, M. and Kimmell, J.R. (1981) Presence of avian pancreatic polypeptide-like immunoreactivity in catecholamine and methionine-enkephalin-containing neurones within the central nervous system. Neurosci. Lett. 21, $125-130$.

Johansson, O., Hökfelt, T., Pernow, B., Jeffcoate, S.L., White, N., Steinbusch, H.W.M., Verhofstad, A.A.J., Emson, P.C. and Spindel, E. (1981) Immunohistochemical support for three putative transmitters in one neuron: coexistence of 5-hydroxytryptamine, substance $\mathrm{P}$-, and thyrotropin releasing hormone-like immunoreactivity in medullary neurons projecting to the spinal cord. Neuroscience 6, 1857-1881.

Jordan, C.L., Breedlove, S.M. and Arnold, A.P. (1982) Sexual dimorphism and the influence of neonatal androgen in the dorsolateral motor nucleus of the rat lumbar spinal cord. Brain Res. 249, 309-314.

Katagiri, T., Gibson, S.J., Su, H.C. and Polak, J.M. (1986) Composition and central projections of the pudendal nerve in the rat investigated by combined peptide immunocytochemistry and retrograde fluorescent labelling. Brain Res. 372, 313-322.

Katagiri, T., Kuzirai, T., Nihei, K., Honda, K., Sasaki, H. and Polak, J.M. (1988) Immunocytochemical study of Onuf's nucleus in amyotrophic lateral sclerosis. Jpn. J. Med. 27, 23-28.

Kawatani, M., Shioda, S., Nakai, Y., Takeshige, C. and de Groat, W.C. (1989) Ultrastructural analysis of enkephalinergic terminals in parasympathetic ganglia innervating the urinary bladder of the cat. J. Comp. Neurol. 288, 81-91,
Kerns, J.M. and Peters, A. (1974) Ultrastructure of a large ventrolateral dendritic bundle in the rat ventral horn. $J$. Neurocytol. 3. 533-555.

Kojima, M., Matsuura, T., Kimura, H., Nogyo, Y. and Sano, Y. (1984) Fluorescence histochemical study on the noradrenergic control to the anterior column of the spinal lumbosacral segments of the rat and dog, with special reference to motoneurons innervating the perineal striated muscles (Onuf's nucleus). Histochemistry 81 . 237-241.

Kojima, M., Matsuura, T., Tanaka, A., Amagai, T., Imanishi, J. and Sano, Y. (1985) Characteristic distribution of noradrenergic terminals on the anterior horn motoneurons innervating the perineal striated muscles in the rat. Anat. Embryol. 171, 267-273.

Konishi, A., Sato, M., Mizuno, N., Itoh, K., Nomura, S. and Sugimoto, T. (1978) An electron microscope study of the areas of the Onuf's nucleus in the cat. Brain Res. 156, 333-338.

Konishi, A., Itoh, K., Sugimoto, T., Yasui, Y., Kaneko, T., Takada, M. and Mizuno, N. (1985) Leucine-enkephalin-like immunoreactive afferent fibers to pudendal motoneurons in the cat. Neurosci. Lett. 61, 109-113.

Kuzuhara, S., Kanazawa, I. and Nakanishi, T. (1980) Topographical localization of the Onuf's nuclear neurons innervating the rectal and vesical striated sphincter muscles: a retrograde fluorescent double labeling in cat and dog. Neurosci. Lett. 16, 125-130.

Lechan, R.M., Snapper, S.B., Jacobson, S. and Jackson, I.M.D (1984) The distribution of thyrotropin-releasing hormone (TRH) in the Rhesus monkey spinal cord. Peptides 5, Suppl. 1, 185-194.

Léger, L., Charnay, Y., Dubois, P.M. and Jouvet, M. (1986) Distribution of enkephalin-immunoreactive cell bodies in relation to serotonin-containing neurons in the raphe nuclei of the cat: immunohistochemical evidence for the coexistence of enkephalins and serotonin in certain cells. Brain Res. 362, 63-73.

Ljungdahl, A., Hökfelt, T. and Nilsson, G. (1978) Distribution of substance P-like immunoreactivity in the central nervous system of the rat. I. Cell bodies and nerve terminals. Neuroscience 3, 861-943.

Mannen, T., Iwata, M., Toyokura, Y. and Nagashima, K. (1977) Preservation of a certain motoneurone group of the sacral cord in amyotrophic lateral sclerosis: its clinical significance. J. Neurol. Neurosurg. Psychiat. 40, 464-469.

Marson, L. and McKenna, K.E. (1992) A role for 5hydroxytryptamine in descending inhibition of spinal sexual reflexes. Exp. Brain Res. 88, 313-320.

Matsumoto, A., Micevych, P.E. and Arnold, A.P. (1988) Androgen regulates synaptic input to motoneurons of the adult rat spinal cord. J. Neurosci. 8, 4168-4176.

Matthews, M.A., Willis, W.D. and Williams, V. (1971) Dendrite bundles in lamina IX of cat spinal cord: a possible source for electrical interaction between motoneurons? Anat. Rec. 171, 313-328.

McKenna, K.E. and Nadelhaft, I. (1986) The organization of the pudendal nerve in the male and female rat. J. Comp. Neurol. 248 , 532-549.

Micevych, P.E., Coquelin, A. and Arnold, A.P. (1986) Immunohistochemical distribution of substance $P$, serotonin, and methionine enkephalin in sexually dimorphic nuclei of the rat lumbar spinal cord. J. Comp. Neurol. 248, 235-244.

Millhorn, D.E., Hökfelt, T., Verhofstad, A.A.J. and Terenius, L. (1989) Individual cells in the raphe nuclei of the medulla oblongata in rat that contain immunoreactivities for both serotonin and enkephalin project to the spinal cord. Exp. Brain Res. 75, 536-542.

Onuf, B. (1900) On the arrangement and function of the cell groups of the sacral region of the spinal cord in man. Arch. Neurol. Psychopathol. 3, 387 412.

Priestley, J.V. and Cuello, A.C. (1983) Electron microscopic immunocytochemistry for CNS transmitters and transmitter markers. In IBRO Handbook Series: Methods in the Neurosciences, Vol. 3. Immunocytochemistry (ed. Cuello, A.C.), pp. 273-322. Wiley, Chichester. 
Rajaofetra, N., Passagia, J.G., Marlier, L., Poulat, P., Pellas, F., Sandillon, F., Verschuere, B., Gouy, D., Geffard, M. and Privat, A. (1992) Serotoninergic, noradrenergic, and peptidergic innervation of Onuf's nucleus of normal and transected spinal cords of baboons (Papio papio). J. Comp. Neurol. 318, 1-17.

Ramirez-León, V. and Ulfhake, B. (1993) GABA-like immunoreactive innervation and dendro-dendritic contacts in the ventrolateral dendritic bundle in the cat $\mathrm{S} 1$ spinal cord segment: an electron microscopic study. Exp. Brain Res. 97, 1-12.

Ramírez-León, V., Hökfelt, T. and Ulfhake, B. (1993) Peptidergic and GABAergic innervation of the ventrolateral dendritic bundle in the cat S1 spinal cord segment. Soc. Neurosci. Abstr. 19 (2), 984.

Ramírez-León, V., Ulfhake, B., Arvidsson, U., Verhofstad, A.A.J., Visser, T.J. and Hökfelt, T. (1994) Serotoninergic, peptidergic and GABAergic innervation of the ventrolateral and dorsolateral motor nuclei in the cat S1/S2 segments: an immunofluorescence study. J. Chem. Neuroanat., 7, 87-103.

Romagnano, M.A. and Hamill, R.W. (1985) Spinal parasympathetic enkephalin fibers: patterns and projections. Brain Res. 335 . 174-181

Romagnano, M.A., Braiman, J., Loomis, M. and Hamill, R.W. (1987) Enkephalin fibers in autonomic nuclear regions: intraspinal vs. supraspinal origin. J. Comp. Neurol. 266, 319-331.

Romanes, G.J. (1951) The motor cell columns of the lumbosacral spinal cord of the cat. J. Comp. Neurol. 94, 313-363.

Roney, K.J., Scheibel, A.B. and Shaw, G.L. (1979) Dendritic bundles: survey of anatomical experiments and physiological theories. Brain Res. Rev. 1, 225-271.

Rudomin, P. (1990) Presynaptic inhibition of muscle spindle and tendon organ afferents in the mammalian spinal cord. Trends Neurosci. 13, 499-505.

Sato, M., Mizuno, N. and Konishi, A. (1978) Localization of motoneurons innervating perineal muscles: a HRP study in cat. Brain Res. 140, 149-154.

Scheibel, M.E. and Scheibel, A.B. (1970) Organization of spinal motoneuron dendrites in bundles. Exp. Neurol. 28, 106-112.

Schreder, H.D. (1980) Organization of the motoneurons innervating the pelvic muscles of the male rat. J. Comp. Neurol. 192, 567-587.

Schrøder, H.D. (1984) Somatostatin in the caudal spinal cord: an immunohistochemical study of the spinal centers involved in the innervation of the pelvic organs. J. Comp. Neurol. 223, 400-414.

Staines, W.A., Meister, B., Melander, T., Nagy, J.I. and Hökfelt, T. (1988) Three-color immunofluorescence histochemistry allowing triple labeling within a single section. J. Histochem. Cytochem. 36, 145-151.

Steinbusch, H.W.M., Verhofstad. A.A.J. and Joosten, H.W.J. (1978) Localization of serotonin in the central nervous system by immunohistochemistry: description of a specific and sensitive technique and some applications. Neuroscience 3, 811-819.

Sternberger, L.A., Hardy, P.H., Cuculis, J.J. and Meyer, H.G. (1970) The unlabeled antibody enzyme method of immunohistochemistry. Preparation and properties of soluble antigen-antibody complex (horseradish peroxidase-antihorseradish peroxidase) and its use in identification of spirochetes. J. Histochem. Cytochem. 18, 315-333.

Sung, J.H. (1982) Autonomic neurons of the sacral spinal cord in amyotrophic lateral sclerosis, anterior poliomyelitis and 'neuronal intranuclear hyaline inclusion disease': Distribution of sacral autonomic neurons. Acta Neuropathol. (Berl.) 56, 233-237.

Suzuki, T., Oka, J., Nagano, N. and Fukuda, H. (1986) Enkephalin but not morphine modulates the motor activity in the frog spinal cord in vitro. Comp. Biochem. Physiol. 83C, 245-251.

Tappaz, M.L., Zivin, J.A. and Kopin, I.J. (1976) Intraspinal glutamic decarboxylase distribution after transection of the cord at the thoracic level. Brain Res. 111, 220-223.

Tashiro, T. and Ruda, M.A. (1988) Immunocytochemical identification of axons containing coexistent serotonin and substance $\mathbf{P}$ in the cat lumbar spinal cord. Peptides 9, 383-391.
Tashiro, T., Satoda, T., Takahashi, O., Matsushima, R. and Mizuno, N. (1988) Distribution of axons exhibiting both enkephalin- and serotonin-like immunoreactivities in the lumbar cord segments: an immunohistochemical study in the cat. Brain Res. 440, 357-362.

Tashiro, T., Satoda, T., Matsushima, R. and Mizuno, N. (1989a) Convergence of serotonin-, enkephalin- and substance P-like immunoreactive afferent fibers on single pudendal motoneurons in Onuf's nucleus of the cat: a light microscope study combining the triple immunocytochemical staining technique with the retrograde HRP. tracing method. Brain Res. 481, 392-398.

Tashiro, T., Satoda, T., Matsushima, R. and Mizuno, N. (1989b) Possible origins of substance P-like immunoreactive axons within Onuf's nucleus of the cat. Brain Res. 497, 177-182.

Tessler, A., Glazer, E., Artymyshyn, R., Murray, M. and Goldberger. M.E. (1980) Recovery of substance $P$ in the cat spinal cord after unilateral lumbosacral deafferentation. Brain Res. 191, 459-470.

Tessler, A.. Himes, B.T., Artymyshyn, R.. Murray, M. and Goldberger, M.E. (1981) Spinal neurons mediate return of substance $\mathbf{P}$ following deafferentation of cat spinal cord. Brain Res. 230, 263-281.

Ueyama, T., Mizuno, N., Nomura, S., Konishi. A., Itoh, K. and Arakawa, H. (1984) Central distribution of afferent and efferent components of the pudendal nerve in cat. J. Comp. Neurol. 222. 38-46.

Ulfhake, B. and Kellerth, J.-O. (1981) A quantitative light microscopic study of the dendrites of cat spinal $\alpha$-motoneurons after intracellular staining with horseradish peroxidase. J. Comp. Neurol. 202. $571-583$.

Ulfhake, B. and Kellerth, J.-O. (1983) A quantitative morphological study of HRP-Iabelled cat $\alpha$-motoneurones supplying different hindlimb muscles. Brain Res. 264, 1-19.

Ulfhake, B., Arvidsson, U., Cullheim, S., Hökfelt, T., Brodin, E., Verhofstad, A. and Visser, T. (1987a) An ultrastructural study of 5-hydroxytryptamine-, thyrotropin-releasing hormone- and substance P-immunoreactive axonal boutons in the motor nucleus of spinal cord segments $\mathrm{L} 7-\mathrm{S} 1$ in the adult cat. Neuroscience 23. $917-929$

Ulfhake, B., Cullheim, S., Hökfelt, T. and Visser, T.J. (1987b) The combined use of immunohistochemistry and intracellular staining with horseradish peroxidase for light and electron microscopic studies of transmitter-identified inputs to functionally characterized neurons. Brain Res. 419, 387-391.

Visser, T.J., Klootwijk, W., Docter, R. and Hennemann. G. (1978) A different approach to the radioimmunoassay of thyrotrophinreleasing hormone. In Radioimmunoassay and Related Procedures in Medicine 1977. Vol. II, pp. 469-477. IAEA, Vienna.

Wessendorf, M.W. and Elde, R.P. (1985) Characterization of an immunofluorescence technique for the demonstration of coexisting neurotransmitters within nerve fibers and terminals. $J$. Histochem. Cytochem. 33, 984-994.

Wessendorf, M.W., Appel, N.M., Molitor, T.W. and Elde, R.P. (1990) A method for immunofluorescent demonstration of three coexisting neurotransmitters in rat brain and spinal cord, using the fluorophores fluorescein, lissamine rhodamine, and 7-amino-4 metylcoumarin-3-acetic acid. J. Histochem. Cytochem. 38, 1859-1877.

White, S.R. (1985) Serotonin and co-localized peptides: effects on spinal motoneuron excitability. Peptides 6. Suppl. 2, 123-127.

Willingham. M.C. (1983) An alternative fixation-processing method for preembedding ultrastructural immunocytochemistry of cytoplasmic antigens: the GBS (glutaraldehyde-borohydride-saponin) procedure. J. Histochem. Cytochem. 31, 791-798.

Zieglgänsberger, W. and Tulloch, I.F. (1979) The effects of methionine- and leucine-enkephalin on spinal neurones of the cat. Brain Res. 167, 53-64. 